\title{
Boundary tones and the semantics of the Dutch final particles hè, hoor, zeg and joh
}

\author{
Robert S. Kirsner and Vincent J. van Heuven
}

\section{Introduction}

When meanings are combined in an utterance, they may work either synergistically, to communicate a coherent message, or antagonistically. ${ }^{1}$ In the sentence Waar ben je verder nog geweest? 'Where else were you?' the combination of verder nog 'else' with zijn 'to be' is synergistic; since it is possible for people to go to many places, it makes sense to ask what additional places (other than those already mentioned) the hearer has visited. In ?Waar ben je verder nog geboren? 'Where else were you born?', on the other hand, verder nog clashes with geboren worden 'be born', an event normally held to happen only once, hence in a unique spatio-temporal location.

Because intonation communicates meanings analogous to (if not strictly comparable to) those signaled by grammar and lexicon, one expects to find here, too, examples of synergy and antagonism. One illustration might be the contrast between the utterance Zuster! 'Nurse!' (when spoken - or screamed - with socalled 'street call' intonation (configuration $1 \mathrm{E}$ in 't Hart, Collier \& Cohen 1990) in order to summon a nurse to a ward where a patient is undergoing a medical emergency) and the utterance God! 'id.', produced with the same intonation. Since the Almighty is conventionally conceived of as omniscient, omnipotent, and omnipresent, it is relatively incoherent for a Dutch speaker to address Him in a way which suggests that $\mathrm{He}$ is somehow absent from where the speaker is and/or otherwise answerable to the speaker, the way a nurse would be to those standing at a patient's bedside. Native speakers accordingly judge God!, with 'street-call' intonation, to be strange. If a foreign linguist did not know the meaning of the lexeme God, its observed incoherence with 'street call' intonation would at least suggest that the referent(s) of God could not be summoned in the same way that people can be.

Our paper describes the use of a particular intonational contrast as a tool in analyzing the semantics of the Dutch utterance-final particles hè, hoor, zeg, and

1 Kirsner's work was supported by NWO Bezoekersbeurs B 33-215 and by Grant 2964 from the Academic Senate of the University of California, Los Angeles. We wish to acknowledge Dr. Michael Mitchell of the Office of Academic Computing, UCLA, for discussion of the statistical analysis. 
$j o h .^{2}$ We will show that the relative (in)coherence of these particles in utterances with different boundary tones reflects crucial differences in their underlying semantics.

\section{The high boundary tone $H \%$ and the low boundary tone $L$}

As discussed in 't Hart et al. (1990), Dutch intonation domains (roughly equivalent to short sentences or clauses) typically end on either the low declination line or the high declination line. The domain-final syllables are labelled, in autosegmental terminology, as the low tone $\mathrm{L}$ and the high boundary tone $\mathrm{H} \%$, respectively (Van den Berg, Gussenhoven \& Rietveld 1992). The semantic contrast between them has traditionally been described as 'assertion' versus 'question', but Keijsper (1984) points out that the association of $L$ and $H \%$ with these messages is far from ironclad. In the present study, we make use of our earlier proposal that $\mathrm{H} \%$ indicates an APPEAL from the speaker to the hearer, while L indicates NO APPEAL (Kirsner, van Heuven \& van Bezooijen 1994: 108$9,117)$. Depending on the context, APPEAL can be interpreted as a request for the hearer's continued attention, for a verbal reply from the hearer, or for non-verbal compliance of some kind by the hearer.

\section{The particles}

2.1 The hoor-hè system. We assume as a working hypothesis our analysis of hoor and hè as sharing certain components of meaning but also forming a semantic opposition, much like the pairs of English discourse markers now and then, or $I$ mean and y'know, discussed in Schiffrin 1987; cf. Kirsner \& Deen (1990) and Kirsner et al. (1994: 108). Specifically, both hoor and hè claim that there is some personal relationship between speaker and hearer and both instruct the hearer to pay particular attention to the material immediately prior to the particle. But whereas hè asks the hearer for some sort of confirmation, or at least acknowledgment, hoor indicates that nothing of the kind is needed or wanted. Compare (1):

2 Though Geerts et al. (1984: 676) classify these elements as interjections, we will retain the more general term 'particle' here. We limit ourselves to their use in utterance-final position. (Compare, for example, De Vriendt's distinction (1995: 156-7) between $z e g_{1}$ and $z e g_{2}$.) 
(1) a Jij komt morgen ook, hoor. you come tomorrow too, hear

'You be sure to come tomorrow!/You're coming tomorrow, mind you'

b Jij komt morgen ook, hè?

you come tomorrow too, eh

'You're coming tomorrow too, aren't you?'

Observe that the two particles, being mutually contradictory, cannot be combined; cf. *Jij komt morgen ook, hoor hè? or *Jij komt morgen ook, hè hoor.

That both hoor and hè indicate a relationship between speaker and hearer is shown by the fact that whereas the expression dag 'day' can be used with someone's name or title, to say 'hello' as well as 'goodbye', neither hoor nor hè typically occur in initial greetings: One has Dag Jan! 'Hello Jan' but not *Dag hoor Jan! or *Dag Jan hoor! or *Dag hè Jan? or *Dag Jan hè? Since the speaker has to use the addressee's name or title to attract his or her attention in the first place, there is, strictly speaking, no relationship between speaker and hearer yet for hoor or hè to refer to, whence the incoherence as initial greetings of sentences containing hoor and hè. In consequence, though dag DOES combine with both hè and hoor, it is interpreted in the collocations Dag hoor and Dag hè only as 'goodbye' and not as 'hello.'

We note further that the interpretations which Dag hoor and Dag hè receive as farewells make exquisite sense in terms of the opposition we have postulated. If Nou dag! 'Well goodbye' is a normal end to a conversation, Nou dag hoor suggests that the speaker is having difficulty extricating himself from the conversation; he has to focus the hearer's attention on the goodbye, suggesting that the hearer had not been paying attention before. Nou dag hè 'Well goodbye, OK?', in turn, requests the hearer's acknowledgement that the speaker is leaving.

2.2 Zeg. For present purposes, we adopt De Vriendt's analysis (1995: 158) that final zeg contrasts with hoor in expressing only the speaker's own concern with, or own degree of involvement with, the linguistic material preceding the particle, without reference to a relationship with a hearer. It follows from this that zeg but not hoor - can be used in utterances expressing the speaker's own pure surprise at some novel state of affairs, without regard for the hearer. Compare (2): 
(2)
a Wat een mooi strand, zeg!
what a pretty beach, say
'Wow, what a pretty beach!'
c Wat een mooi strand, hè?
what a pretty beach, eh
'What a pretty beach, isn't it?'

b *Wat een mooi strand, hoor!

what a pretty beach, hear

'What a pretty beach, mind you.'

In contrast to zeg, use of hoor, explicitly profiling the speaker-hearer relationship (in the sense of Langacker 1991), suggests that the speaker is not only fully and spontaneously taken with the beauty of the beach but also - at the very same time - wants to interact with the hearer, to suggest that the hearer had not been paying enough attention to the state of affairs depicted by the wat-sentence, of which the speaker had just become aware. This undercuts the message of pure and total surprise, leading to incoherence (cf. Mooi strand, hoor!, without wat, which does not communicate such an overwhelming level of surprise and, hence, is more compatible with hoor). Conversely, hè, requesting confirmation or acknowledgement, contrasts with zeg in that it can be used to 'share' the surprise with the hearer, as in $(2 \mathrm{c})$.

A final observation on zeg and the differences between it and hè and hoor would be that its emotionality, the fact that it expresses only the speaker's own involvement, renders it less useful in greetings, which necessarily involve a hearer: One has Dag hoor and Dag hè but not *Dag, zeg!

2.3 Joh. Having evolved from jongen 'boy, lad', joh is perhaps best viewed as a generic form of address, an in-group identity marker in the sense of Brown \& Levinson (1987: 107-110). Examples of its use to address a hearer are legion: cf. the warning Hé joh, kijk een beetje uit 'Hey you, watch out' and the call of encouragement Kop op, joh 'Come on, old boy'. (Martin \& Tops 1986: 605). The 'emphasis' joh communicates as a final particle derives from this direct address of the hearer, which lets the hearer know that the preceding utterance is relevant explicitly to him.

Because joh can be used to attract a hearer's attention, it does not suggest the existence of an ongoing relationship between speaker and hearer the way that hè and hoor do. Accordingly, unlike hè and hoor, joh can be used together with dag to communicate a greeting, Dag, joh!, which is felt as familiar and 'chummy.'

\section{Predictions}

We now consider how the particles hè, hoor, zeg and joh, and their absence, might interact with the boundary tones $\mathrm{H} \%$ and $\mathrm{L}$. First of all, we might expect that 'plain' or 'bare' utterances, lacking a final particle, would be more accept- 
able, sound more normal with $\mathrm{L}$ than with $\mathrm{H} \%$, and that the reverse would hold true with utterances containing a final particle. That is, if a speaker has available optional particles which add something extra to the propositional content of a sentence (often something designed to impact upon the hearer), then it makes sense that, if he decides NOT to use them, he would also NOT be attempting to directly elicit a reaction or a behavior from the hearer. Hence, the preferred boundary tone for particle-less sentences should be L, signaling NO APPEAL and not $\mathrm{H} \%$, signaling APPEAL. The preferred boundary tone for sentences containing particles should, of course, be $\mathrm{H} \%$ and not $\mathrm{L}$.

Insofar as hè and hoor explicitly profile the relationship between speaker and hearer, we would expect both to be highly compatible with $\mathrm{H} \%$, signaling APPEAL, and relatively incompatible with L, signaling NO APPEAL. Furthermore, since hè contrasts with hoor in requesting either confirmation by (or at least acknowledgement from) the hearer, we would expect it to be even more compatible with $\mathrm{H} \%$ than hoor and even less compatible with $\mathrm{L}$ than hoor.

Because joh (as a form of address) can be used to create a new relationship with a hearer, by attracting his attention, it should certainly be compatible with $\mathrm{H} \%$, though perhaps not as much as hè or hoor, which indicate that the speakerhearer relationship is ongoing, more presupposed. Furthermore, since joh merely addresses the hearer and does not in itself signal any more explicit messages to him, the way that hè and hoor $\mathrm{do}^{3}$, it should be less incompatible with $\mathrm{L}$ than hè and hoor.

Zeg, expressing the speaker's own involvement with what s/he is saying, should be relatively compatible with L, signaling NO APPEAL TO THE HEARER, but less compatible than hè and hoor with $\mathrm{H} \%$, signaling APPEAL. Furthermore, because zeg makes no reference to the hearer while joh is a form of address, zeg should be less compatible with $\mathrm{H} \%$ than $j o h$ is.

Table 1 summarizes the above discussion by listing for each particle the semantic components favoring co-occurrence with $\mathrm{H} \%$ (and hence potential incompatibility with L). Assuming that all factors have equal weight, one predicts the order of increasing compatibility with $\mathrm{H} \%$ to be: No particle $<z e g<j o h$ $<$ hoor $<$ hè.

${ }^{3}$ In addition to attracting the hearer's attention ( $\left.\$ 3.1\right)$ and focussing it on the content of the immediately preceding utterance, hè explicitly signals CONFIRMATION/ACKNOWLEDGEMENT REQUESTED while hoor explicitly signals the directly opposing meaning CONFIRMATION/ACKNOWLEDGEMENT NOT REQUESTED. 
Table 1. Factors favoring high boundary tone $H \%$.

\begin{tabular}{|l|c|c|c|c|c|}
\hline \multirow{2}{*}{\multicolumn{2}{c|}{ SEMANTIC COMPONENTS }} & \multicolumn{5}{c|}{ PARTICLE } \\
\cline { 2 - 7 } & None & zeg & joh & hoor & hè \\
\hline Focusses extra attention on utterance & - & + & + & + & + \\
\hline Explicitly involves hearer & - & - & + & + & + \\
\hline Profiles ongoing speaker-hearer relationship & - & - & - & + & + \\
\hline Explicitly requests acknowledgement from hearer & - & - & - & - & + \\
\hline NUMBER OF FACTORS FAVORING H\% & 0 & 1 & 2 & 3 & 4 \\
\hline
\end{tabular}

\section{Experiment}

Two sentences were chosen as stimulus material: the relatively neutral factual sentence Dertien is een priemgetal 'Thirteen is a prime number', used previously in Kirsner et al. (1994), and the potentially more emotional and more contextdependent sentence Zo is het niet gegaan 'It did not work out that way.' Each sentence was combined with final hè, hoor, zeg, or joh, and also used 'bare', i.e. without particle. Eight spoken versions of each sentence were prepared: four ending on the boundary tone $\mathrm{H} \%$ and four ending on $\mathrm{L}$. The sentences were also prepared with different accentual patterns, in order to study the potential influence of accent-linking and accent de-linking. One version was recorded with accent-linking (the 'flat-hat pattern') and three with different kinds of accent delinking: the 'pointed hats' intonation contour, the 'sawtooth' contour, and with 'inclination.' This yielded 2 sentences $\times 5$ particles (including 'none') $\times 2$ endings $\mathrm{x} 4$ intonation contours, or 80 stimuli (for speech resynthesis procedures followed, see Kirsner et al. 1994: 110-1).

Two tapes were prepared, one with the test sentences recorded in one random order, the other in the reverse random order. Forty native speakers of Dutch (twenty for each tape) listened to the set of 80 stimuli five times and, in successive trials, rated each sentence on five different 9-point scales. In the present paper, we will be concerned almost exclusively with the ratings on just one of these: the unusual-usual scale, which we will call 'Usualness'. We will, however, marginally discuss results on the distant-emotional scale, which we will call 'Emotionality'4. The instructions to the experimental subjects in these two cases were as follows:

4 The remaining three scales were. predictable-unexpected, reproachful-content, full-of-oneself-modest. 
How USUAL or UNUSUAL does the sentence sound? How easily can you think of situations in which the sentence would be said the way you heard it?

\begin{tabular}{|c|c|c|}
\hline $\begin{array}{l}\text { UNUSUAL, NO } \\
\text { CONTEXT OR } \\
\text { SITUATION POSSIBLE }\end{array}$ & $<=123456789=>$ & $\begin{array}{r}\text { USUAL, MANY } \\
\text { CONTEXTS OR } \\
\text { SITUATIONS POSSIBLE }\end{array}$ \\
\hline $\begin{array}{l}\text { DISTANT, } \\
\text { UNMOVED, } \\
\text { COOL }\end{array}$ & $<=12234566789=>$ & $\begin{array}{l}\text { EMOTIONAL, } \\
\text { INVOLVED, } \\
\text { PASSIONATE }\end{array}$ \\
\hline
\end{tabular}

\section{Results}

5.1 Usualness scores. A repeated measures analysis of variance of the Usualness scale judgements showed that the following factors and interactions were significant at the .01 level (or better) and explained at least $1 \%$ of the variance ${ }^{5}$.

Table 2. Summary of analysis of varance on the Usualness scale.

\begin{tabular}{|l|l|r|}
\hline Factor/Interaction & Significance & Omega squared \\
\hline Sentence & $\mathrm{F}(1,39)=21.11, \quad \mathrm{p}<.001$ & $3.78 \%$ \\
Particle & $\mathrm{F}(4,156)=23.43, \quad \mathrm{p}<.001$ & $3.86 \%$ \\
Boundary tone & $\mathrm{F}(1,39)=96.55, \quad \mathrm{p}<.001$ & $12.57 \%$ \\
Particle*Boundary tone & $\mathrm{F}(4,156)=61.45, \quad \mathrm{p}<.001$ & $10.36 \%$ \\
\hline
\end{tabular}

Figure 1 plots the mean Usualness score for both sentences, combined, as a function of boundary and particle type, with the particles listed in the order given in Table 1.

5 As represented by omega squared $\left(\omega^{2}\right)$, cf the discussion of estımatıng relative treatment magnitude in Keppel (1982 89-96, 204) See also Rietveld \& Van Hout (1993 58-60) All repeated measures analyses of variance reported on here were performed with the SPSS MANOVA procedure, with Sentence, Partıcle, Boundary Tone, etc, specified as withın-subjects factors (cf Norušıs 1990 Ch 4) 


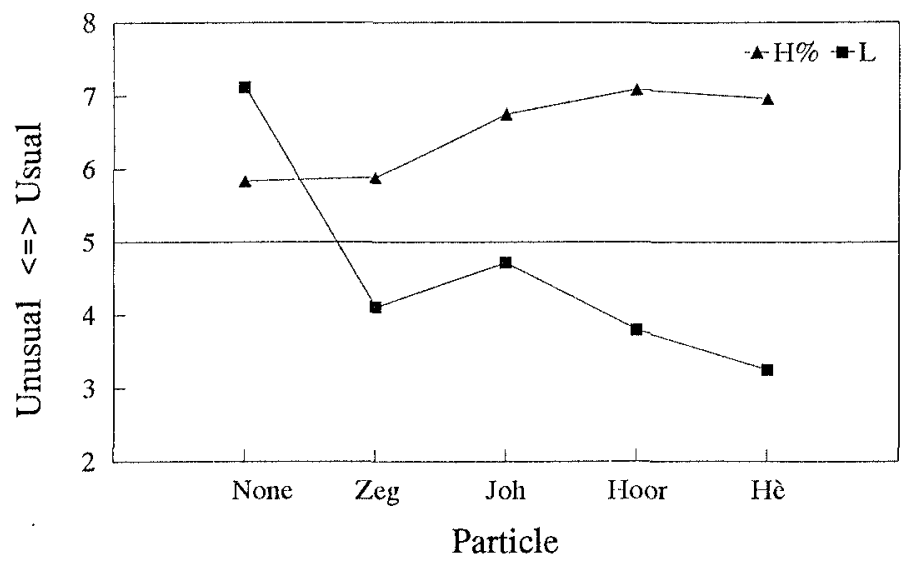

Figure 1. Mean Usualness scores for both sentences combined broken down by type of final particle and boundary tone.

It will be seen, first of all, that the main features of the prediction in $\$ 3$ are confirmed. As one proceeds from 'plain' sentences with no particle to zeg to joh to hoor and then to hè, the Usualness scores for the $\mathrm{H} \%$-sentences move upwards (from less to more Usual) while those for the L-sentences move downwards. Sen tences without a particle (labelled None) are indeed judged more normal with final $\mathrm{L}$ than with final $\mathrm{H} \%$, and the reverse holds for all the sentences with particles. Furthermore, that particle which sounds least normal with $\mathrm{H} \%$ is zeg, as predicted, with a mean rating of 5.88 on the 9-point scale, while that particle which sounds least normal with $\mathrm{L}$ is $h \grave{e}$, also as predicted, with a mean rating of 3.25 .

What is apparent from Figure 1 is confirmed by analyses of variance (within subjects design). Planned comparisons show that, for sentences containing particles, the Usualness scores with $\mathrm{H} \%$ are significantly lower for $z e g(\mathrm{p}<.001)$ than for joh, hoor, and hè and that the Usualness scores with $\mathrm{L}$ are likewise significantly lower for hè $(\mathrm{p}<.001)$ than for hoor, joh, and zeg. It makes eminent sense, of course, that the particle zeg, which according to De Vriendt does NOT involve the hearer, would be the least felicitous with $\mathrm{H} \%$, signaling APPEAL TO HEARER, and that hè, which the speaker uses to explicitly underscore relationship with the hearer and to explicitly ask the hearer's acknowledgement, would be the least felicitious with L, signaling NO APPEAL TO HEARER. The observed clashes between particle and boundary tone supports the semantic analysis of these particles offered in $\S 2$. 
5.2 The 'Difference in usualness' scores. It is nevertheless clear that Figure 1 does not fully fit the predictions of $\S 3$ : There are unexplained fluctuations in the values. Though the $\mathrm{H} \%$-line increases by and large, the data for the $\mathrm{H} \%$-sentences seem to level off at $j o h$. And though the data for the L-sentences decreases by and large, zeg is unexpeciedly worse than joh.

A more direct test of the ranking in Table 1 would be provided by calculating, for each of the 40 experimental subjects, the DIFFERENCE $(\Delta)$ between the Usualness ratings under $\mathrm{H} \%$ and the Usualness rating under $\mathrm{L}$ for each combination of sentence, particle, and intonation contour. One could then control for unpredicted fluctuations in the absolute value of the $\mathrm{H} \%$ and $\mathrm{L}$ lines. Certainly if the Usualness scores for the particles None, zeg, joh, hoor and hè increase (in this order) in the $\mathrm{H} \%$ sentences (reflecting their increasing semantic compatibility with $\mathrm{H} \%$ ), then not only should the Usualness scores decrease in the same order in the L-sentences, but the difference between the two scores should also increase. In other words, the more compatible a particle is with the meaning APPEAL, the greater should be the relative 'advantage' of that particle with $\mathrm{H} \%$ (signaling APPEAL) rather than $\mathrm{L}$ (signaling NO APPEAL). The relevant data are graphed in Figure 2.

Analysis of variance shows that the only significant factor accounting for more than $1 \%$ of the variance $\left(\omega^{2}>1\right)$ is PARTICLE, with $F(4,144)=54.47$, $\mathrm{p}<.001$ and $\omega^{2}=30 \%$. A series of planned comparisons shows that the data exhibit significant linear, quadratic, and cubic trends. Clearly, the more semantic components a particle contains favoring $\mathrm{H} \%$, the greater $\Delta$ Usualness $(\mathrm{H} \%-\mathrm{L}$ ): None $(-1.22)$, zeg $(+1.80)$, joh $(+1.95)$, hoor $(+3.25)$ and hè $(+3.75)$. The difference between the means for the plain sentences and all sentences with particles (combined) was significant $(\mathrm{p}<.001)$, as was the difference between the sentences with zeg and joh, combined, and the sentences with he and hoor, combined. The difference between sentences with hè and with hoor was significant at $\mathrm{p}=.03$; the sentences with zeg and with $j o h$ were not significantly different. Accordingly, there is empirical evidence for the progression None < $z e g$, joh $<$ hoor $<$ hè.

\section{Interim discussion}

In Figure 2, note first that there is a gap of more than 1.25 points on the Usualness scale between hè, hoor on the one hand and zeg, joh on the other. This suggests that the simplifying assumption in $\$ 3$ is incorrect, i.e. that not all 'features' or semantic components count equally. Certainly the meaning EXPLICITLY PROFILES THE SPEAKER HEARER RELATIONSHIP hypothesized to be shared by only hè and hoor may be especially compatible with the meaning APPEAL TO HEARER signaled by $\mathrm{H} \%$ and thereby serve to increase the gap between each of these particles, on the one hand, and joh and zeg on the other. 


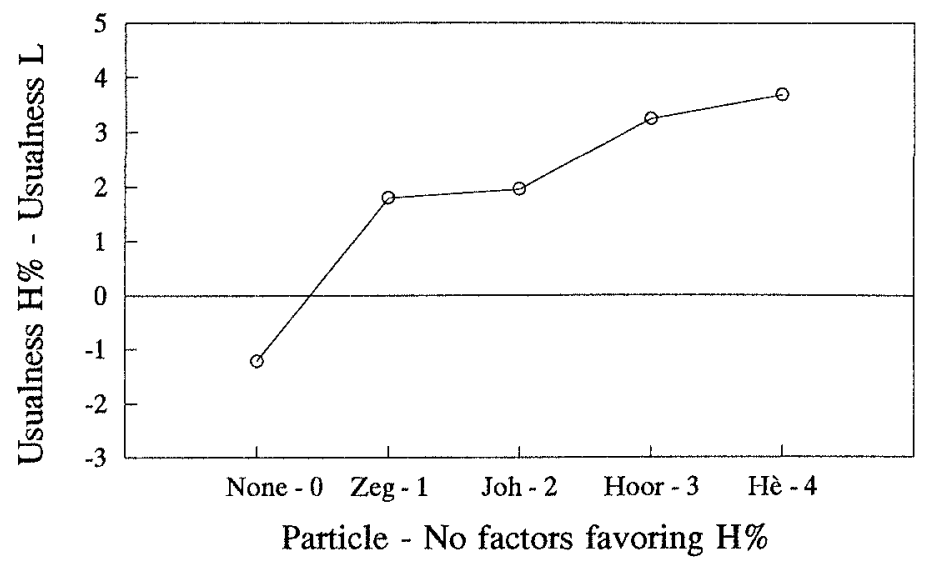

Figure 2. Difference between the Usualness score under H\% and the Usualness score under $L$ for both sentences, broken down by particle, with the particles ranked according to number of semantic components favoring co-occurrence with $H \%$.

Note second the lack of a significant difference between joh and zeg in Figure 2, which might suggest an inadequacy in our semantic analysis. If we return to Figure 1 , we note that though the $\mathrm{H} \%$-line and L-line diverge in general, they exhibit parallel trajectories between zeg and joh. On the H\%-line, zeg is not appreciably more Usual than None but it is worse than joh. On the L-line, zeg is surprisingly worse than joh. Hence the distance between the two lines remains relatively constant. We suggest that the problem lies in the emotionality of zeg. While not aimed directly at a specific hearer in the manner of joh, hoor, or hè, $z e g$ does communicate a non-matter-of-fact stance of the speaker towards what he is saying. This emotional intensity, in turn, is less compatible with the neutrality of a final low tone (which would suggest that the matter is closed) than the rise to a final high tone (which suggests that the matter is not taken entirely for granted). The connection between emotionality and usualness scores will become clearer once we turn to the remaining factor in the experiment.

\section{Effect of sentence}

Thus far, we have discussed two of the three factors listed in Table 2 which, alone or in interactions, significantly influence the Usualness scores: Particle and Boundary tone. Yet the particular sentence chosen also had a major impact on the scores, being nearly as important as the particle and almost one-third as 
important as the boundary tone, as indicated by the $\omega^{2}$-statistic. The 'encyclopedia sentence' Dertien is een priemgetal was judged as less usual, less likely to be said, than Zo is het niet gegaan, with a mean of 5.02 on the 9-point scale versus 6.08 for the latter. For the sake of completeness, it will be useful to briefly consider this variable . $^{6}$

Interestingly, the Dertien-sentence ranked lower not only in Usualness but also on the Emotionality scale shown in (4) above, with a mean score of 5.07 versus 5.90 for the Zo-sentence. Analysis of variance showed that the influence of sentence on judgements of Emotional - Distant was highly significant, $\mathrm{F}(1,37)=61.66\left(\mathrm{p}<.002 ; \omega^{2}=4 \%\right)$. Accordingly, one might want to seek a connection between the Emotionality judgements, on the one hand, and the Usualness judgements on the other.

Because particles and exclamations are normally said to be 'emphatic' (cf. Geerts et al. 1984: 676), we expect them to be more compatible in emotional sentences than non-emotional ones. We might therefore expect that the neutral Dertien-sentence would lag behind the Zo-sentence in Usualness even when both were used with particles. This predicted lag is shown in Figure 3, where we break down the data of Figure 1 by sentence.

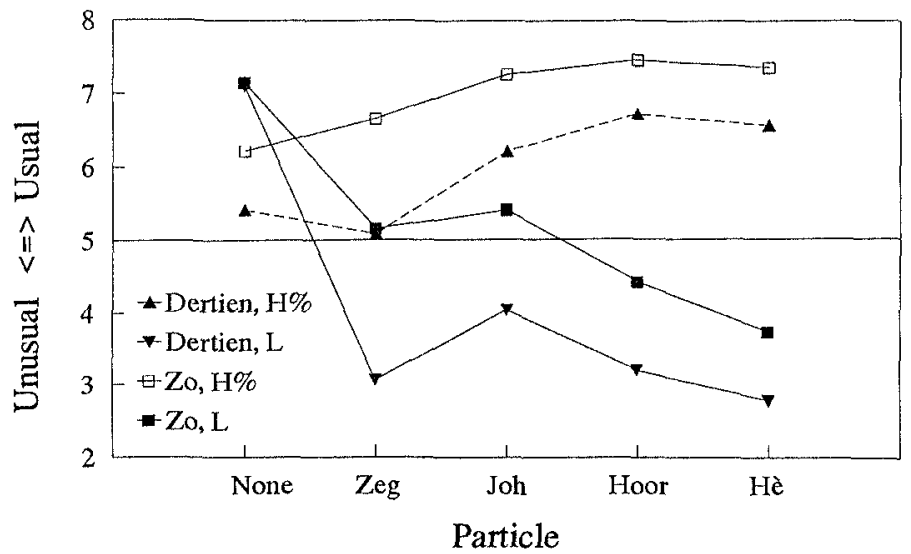

Figure 3. Usualness scores broken down by sentence, boundary tone, and particle.

${ }^{6}$ The two sentences were chosen to maximize the distinction between a factual, context-free sentence and an (emotional) context-bound one. 
We suggest that the reason the Dertien-sentences with $\mathrm{L}$ receive the lowest Usualness ratings is that (outside of a special context) they seem doubly strange: First, they consist of a neutral, encyclopedia sentence combined with a pragmatic particle (normally used in non-neutral sentences). Second, though the resulting combination could in principle be used emphatically or interactively, this option is entirely undercut through the use of the 'wrong' intonation, L. (Whereas the overall mean for the high tone $\mathrm{H} \%$ was 6.38 on the Emotionality scale, the overall mean for $\mathrm{L}$ was 4.60 .) The conflict between sentence, intonation, and particle seems most pronounced with zeg, where the difference between the means for the Dertien-sentence with $\mathrm{H} \%$ and with $\mathrm{L}$ is 2.03 scale points versus only 1.51 for the $Z o$-sentence. The reason seems to be that, in contrast to the other particles (which either attract the hearer's attention or attempt to manipulate him/her), zeg signals strong unadulterated emotional involvement, without more elaborate interactional motives. Though one can use an interactional particle with an encyclopedia sentence to achieve interactional goals (as when one corrects the hearer with Dertien is een priemgetal, hoor, in a schoolroom), it is more difficult to conjure up a context where one would be excited or agitated or indignant, entirely by oneself, about a neutral mathematical fact, especially when prosodic clues do not support such a message.

\section{Conclusions}

In this paper, we have discussed results of an experimental study on the interaction of sentence type, intonation, and pragmatic particles in the interpretation of Dutch sentences. Specifically, native speaker judgements of how normal or usual sentences sound with final rise (H\%), signaling APPEAL and its absence (L), signaling NO APPEAL, provide appreciable intersubjective evidence for the semantic analysis of the particles they contain.

1. That hè is judged least normal/usual in sentences with $\mathrm{L}$ supports the claim that (of the particles considered), it makes the MOST claim upon the hearer. This fits with the analysis of hè as forming a semantic opposition with hoor in which both final particles profile the speaker-hearer relationship and both draw attention to the immediately preceding utterance, but in which hè explicitly requests acknowledgement or confirmation from the speaker while hoor explicitly repudiates it.

2. That zeg (of the particles considered) is least usual with $\mathrm{H} \%$ supports the view that it makes the LEAST claim upon the hearer (which is consonant with De Vriendt's 1992 analysis in which it does not involve the hearer at all).

3. The direction and magnitude of the DIFFERENCE in usualness scores between each sentence with H\% (APPEAL TO HEARER) and with L (NO APPEAL TO HEARER) shows the relative compatability of each particle with $\mathrm{H} \%$ to be 
ordered as follows No particle $<z e g$, joh $<$ hoor $<$ hè This is consistent with the ranking predicted in $\$ 3$ of No particle $<$ zeg $<$ joh $<$ hoor $<$ hè and, hence, with the semantic analysis underlying the prediction

Where the experimental evidence presents an apparent mismatch between prediction and observation (as with the relative ranking of scores for zeg and $j o h$ ) it provides the impetus for further research and refinement of the analysis ${ }^{7}$

\section{References}

Berg, R van den, C Gussenhoven, $T$ Rietveld (1992) 'Downstep in Dutch implications for a model', in G J Docherty and D R Ladd, eds Papers in laboratory phonology II Gesture, segment prosody, Cambridge University Press, Cambridge, 335-359

Brown, Penelope and Stephen C Levinson (1988) Polteness Some universals in language usage (Studies in interactional sociolingustics 4) Cambridge University Press, Cambridge

Geerts, G, W Haeseryn, J de Rooı, M C van den Toorn, eds (1984) Algemene Nederlandse spraakkunst, Wolters Noordhoff, Gronungen

Hart, J 't, R Collier and A Cohen (1990) A perceptual study of intonation An expenmental phonetuc approach to speech melody, Cambridge University, Press, Cambridge

Keijsper, C E (1984) 'Vorm en beteken1s in Nederlandse toonhoogtecontouren', Forum der Letteren $25,2037,113126$

Keppel, Geoffrey $\left(1982^{2}\right)$ Design and analysts A researcher's handbook Prentıce-Hall, Inc , Englewood Cinffs, $\mathrm{N} \mathrm{J}$

Kirsner, Robert S and Jeanine $Y$ Deen (1990) 'Het mes snijdt aan twee kanten On the semantıcs and pragmatics of the Dutch sentence final particle hoor', in M Bruın-Lacy, ed, The Low Countries Multilsctplinary studies Publications of the American Association for Netherlandic Studies 3, University Press of America, Lanham MD, 1-11

Kirsner, Robert S, Vincent J van Heuven and Renée van Bezoojen (1994) 'Interaction of partıcle and prosody in the interpretation of factual Dutch sentences', in R Bok-Bennema and C Cremers, eds Linguistics in the Netherlands 1994, John Benjamms Publishing Company, Amsterdam, $107-$ 118

Langacker, Ronald W (1991) Concept, umage and symbol The cognttve basts of grammar (Cognitive linguistics research 1), Mouton de Gruyter, Berlin

Martin, W and G A J Tops, eds (1986) Van Dale Groot woordenboek Nederlands-Engels, Van Dale Lexicografie, Utrecht/Antwerpen

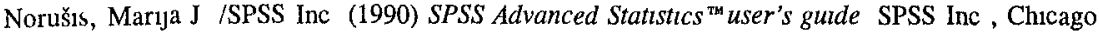

Rietveld, Tonı and Roeland van Hout (1993) Stattstical technques for the study of language and language behaviour Mouton de Gruyter, Berlin and New York

7 Els Elffers inquired why imperatives (which ask for a response from the hearer) do not always occur with $\mathrm{H} \%$ The issue raised here is whether the speaker can demand a response as a right or must request it (or negotiate for $1 \mathfrak{t}$ ) as a favor (which is consistent with the original discussion of the meaning APPEAL in Kirsner et al 1994) A possible analogy to the intonation of imperatives is the use with them of 'softening' particles In some situations, soflening is not possible Note the contrast between Geef acht' 'Ten-HUT' = Attention'', spoken as a command in a military context, and the relatively absurd sentence *Geef eens acht' 'Do pay Ten-HUT'' in the same context 
Schiffrin, Deborah "1987 Discourse markers (Studies in interactional sociolıngustics 5) Cambridge Unıversity Press, Cambridge

Vrıendt, S De (1992) 'Kom', 'kıjk', 'zeg' als interjectie', Studia Neerlandica et Germanica, Wroclaw, 513-520 Reprinted in Sera de Vriendt, Van geen klemtje vervaard Essays over Nederlandse taalwetenschap, VUB Press, Brussel, 1995, 151-159 